\title{
Improving the Performance of PbS Quantum Dot Solar Cells by Optimizing ZnO Window Layer
}

\author{
Xiaokun Yang ${ }^{1,3} \cdot{\text { Long } \mathrm{Hu}^{1} \cdot \text { Hui Deng }}^{1} \cdot \mathrm{Keke} \mathrm{Qiao}^{1} \cdot \mathrm{Chao} \mathrm{Hu}^{1} \cdot \mathrm{Zhiyong} \mathrm{Liu}^{2} \cdot$ Shengjie Yuan $^{1}$ •

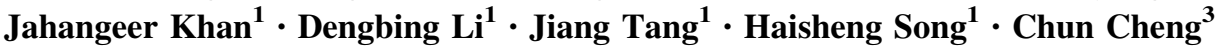

Received: 19 October 2016/Accepted: 29 November 2016/Published online: 4 January 2017

(C) The Author(s) 2017. This article is published with open access at Springerlink.com

\section{Highlights}

- The efficiencies of $\mathrm{PbS}$ solar cells was significantly improved from $4.3 \%$ to $6.7 \%$ by optimizing $\mathrm{ZnO}$ window layer.

- Optimized $\mathrm{ZnO}$ window layer can reduce the surface defects, extend thedepleted-heterojunction width and align with energy band of absorber layer.

\begin{abstract}
Comparing with hot researches in absorber layer, window layer has attracted less attention in $\mathrm{PbS}$ quantum dot solar cells (QD SCs). Actually, the window layer plays a key role in exciton separation, charge drifting, and so on. Herein, $\mathrm{ZnO}$ window layer was systematically investigated for its roles in QD SCs performance. The physical mechanism of improved performance was also explored. It was found that the optimized $\mathrm{ZnO}$ films with appropriate thickness and doping concentration can balance the optical and electrical properties, and its energy band align well with
\end{abstract}

Electronic supplementary material The online version of this article (doi:10.1007/s40820-016-0124-2) contains supplementary material, which is available to authorized users.

Haisheng Song

songhs-wnlo@mail.hust.edu.cn

$\triangle$ Chun Cheng

chengc@sustc.edu.cn

1 Wuhan National Laboratory for Optoelectronics (WNLO) and School of Optical and Electronic Information, Huazhong University of Science and Technology, Wuhan 430074, People's Republic of China

2 State Key Laboratory of Digital Manufacturing Equipment and Technology, Huazhong University of Science and Technology, Wuhan 430074, People's Republic of China

3 Department of Materials Science and Engineering and Shenzhen Key Laboratory of Nanoimprint Technology, South University of Science and Technology, Shenzhen 518055, People's Republic of China

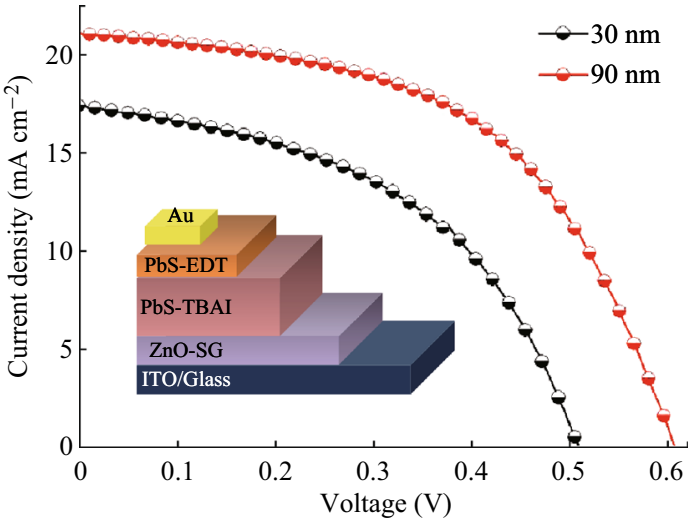

the absorber layer for efficient charge extraction. Further characterizations demonstrated that the window layer optimization can help to reduce the surface defects, improve the heterojunction quality, as well as extend the depletion width. Compared with the control devices, the optimized devices have obtained an efficiency of $6.7 \%$ with an enhanced $V_{\mathrm{oc}}$ of $18 \%, J_{\mathrm{sc}}$ of $21 \%, F F$ of $10 \%$, and power conversion efficiency of $58 \%$. The present work suggests a useful strategy to improve the device performance by optimizing the window layer besides the absorber layer.

Keywords $\mathrm{ZnO}$ - Window layer - Thin film solar cells . $\mathrm{PbS}$ quantum dots $\cdot$ Physical mechanism 


\section{Introduction}

Colloidal quantum dots (CQDs) have attracted significant attention for potentially wide applications in optoelectronic devices such as solar cells [1-3], photodetectors [4-6], and light-emitting diodes $[7,8]$ due to low-temperature fabrication, solution-based processing, and their peculiar optoelectronic properties [9-11]. For solar cell applications, the QDs' bandgap can be conveniently tuned via the quantum size effect in order to match the wide absorption of solar spectra. Furthermore, recently the multi-exciton generation (MEG) effect in CQD-based solar cells (SCs) was reported, which can efficiently utilize high energy photons [1]. The above superior properties enable them as a promising lightabsorbing material. In terms of device architecture, depleted-heterojunction $\mathrm{ZnO}-\mathrm{PbS}$ SCs have achieved the state-of-art highest efficiency and demonstrated the outstanding atmosphere stability [12-14].

In depleted-heterojunction CQD SCs, there were numerous researches for optimizing absorber layers. In contrast, the window layer attracts less attention in spit that it plays the key roles in extracting and transporting charge carriers in heterojunction. As an n-type window layer, $\mathrm{ZnO}$ is an ideal candidate due to its relatively high electron mobility, environment stability, and high transparency [15]. Even utilizing the same window layer of $\mathrm{ZnO}$, different groups utilized varied thickness and obtained over $8 \%$ conversion efficiency $[12,14,16,17]$. Bawvendi et al. utilized $120 \mathrm{~nm} \mathrm{ZnO}$ layer to achieve $8.5 \%$ certified efficiency [14]. Recently, Sargent group adopted $80 \mathrm{~nm} \mathrm{ZnO}$ layer as n-layer and molecular-halide-passivated PbS QDs as absorber to obtain $9.9 \%$ certified efficiency [12]. Considering the optoelectronic function of the window layer, the varied thickness of $\mathrm{ZnO}$ layer needs further optimization for CQD SCs.

For $\mathrm{ZnO}$ layer fabrication, a sol-gel method was commonly used to prepare $\mathrm{ZnO}$ layer due to its low cost and simplicity [18-20]. However, the quality of solution-based $\mathrm{ZnO}$ film suffers from the surface defects or dangling bonds, which may act as charge trap sites or recombination centers [21-23]. To solve the above-mentioned problems, several strategies such as surface passivation or doping were reported to control the interfacial properties of heterojunction [24-28]. All of them have made promising progresses in the improvement of interface quality.

Herein, we adopted a layer-by-layer (LBL) sol-gel method to optimize the $\mathrm{ZnO}$ window layer. The modified sol-gel method could hold stronger capability to obtain smooth junction interface and finely control film processing. On the other hand, each layer deposition was followed one time of annealing. Thus, different $\mathrm{ZnO}$ layer thicknesses were corresponding to varied thermal treatment time as well as varied doping concentration [29, 30]. The performance of $\mathrm{ZnO}-\mathrm{PbS}-\mathrm{QD}$ solar cells was improved by optimizing $\mathrm{ZnO}$ window layer. The physical mechanism was also systematically investigated. Our work was expected to support an efficient routine for device performance improvement.

\section{Experimental Section}

\subsection{Synthesis of PbS Quantum Dots}

$\mathrm{PbS}$ CQDs were synthesized according to the modified literature method [31]. In this work, $0.9 \mathrm{~g}$ lead oxide $(\mathrm{PbO}$, $99.9 \%$ ) and $3 \mathrm{~mL}$ oleic acid (OA, 90\%) were mixed with $20 \mathrm{~mL}$ 1-octadecene (ODE, 90\%) in a 50-mL three-neck flask. The mixture was stirred and degassed at room temperature for $8 \mathrm{~h}$ and heated to $90{ }^{\circ} \mathrm{C}$ for $2 \mathrm{~h}$. The obtained solution was then heated to $100{ }^{\circ} \mathrm{C}$ under nitrogen for $5 \mathrm{~min}$, followed by injection of TMS (hexamethyldisilathiane (bis (trimethylsilyl) sulfide) solution (300 $\mu \mathrm{L}$ TMS mixed with $10 \mathrm{~mL}$ pre-degassed ODE) at $90{ }^{\circ} \mathrm{C}$. After the reaction, the resulting solution was cooled to room temperature naturally. The obtained product was washed and purified 4 times by dispersion/precipitation in hexane/acetone. Finally, the cleaned QDs were dispersed in hexane and octane $($ vol:vol $=4: 1)$ mixed solvents with $\sim 15 \mathrm{mg} \mathrm{mL}^{-1}$ to be ready for use.

\subsection{Layer-by-Layer Sol-Gel Method Deposition of $\mathrm{ZnO}$ Film}

The $\mathrm{ZnO}$ precursor was prepared by dissolving $1.5 \mathrm{~g}$ zinc acetate dehydrate $\left(\mathrm{Zn}(\mathrm{Ac})_{2} \cdot 2 \mathrm{H}_{2} \mathrm{O}\right.$, sinopharm, $\left.99 \%\right)$ and $400 \mu \mathrm{L}$ ethanolamine $\left(\mathrm{NH}_{2} \mathrm{CH}_{2} \mathrm{CH}_{2} \mathrm{OH}\right.$, sinopharm, $\left.99 \%\right)$ in $20 \mathrm{~mL}$ 2-methoxyethanol $\left(\mathrm{CH}_{3} \mathrm{OCH}_{2} \mathrm{CH}_{2} \mathrm{OH}\right.$, sinopharm, 99\%) under vigorous stirring at $60{ }^{\circ} \mathrm{C}$ for $10 \mathrm{~h}$ for the hydrolysis reaction in air. On a precleaned ITO/glass substrate, $\mathrm{ZnO}$ precursor solution was spin-coated at $4000 \mathrm{r}$ $\min ^{-1}$ for $30 \mathrm{~s}$ and annealed at $400{ }^{\circ} \mathrm{C}$ for $15 \mathrm{~min}$, followed by repeating this process some times to reach the required thickness.

\subsection{Device Fabrication}

$\mathrm{PbS}$ CQD films were fabricated by layer-by-layer spincoating according to the published reports [14]. For tetrabutylammonium iodide (TBAI) ligand exchange process, QDs dispersed in hexane/octane mixed solvents was dropped on $\mathrm{ZnO}$-coated substrate and then immediately 
spinned at $2500 \mathrm{r} \mathrm{min}^{-1}$ for $10 \mathrm{~s}$. The obtained film was soaked in TBAI (10 mg mL $\mathrm{mL}^{-1}$ in methanol) solution for 1 min, followed by two-time methanol rinsing. This process obtained a TBAI-treated QD layer and the number of layers was 10-12. For PbS-EDT (1,2-ethanedithiol) layer, $0.01 \mathrm{vol} \%$ EDT/acetonitrile solution was used and spinned after $30 \mathrm{~s}$ soaking, which was followed by a 3-time acetonitrile rinsing. This process was repeated two times. The total thickness of PbS CQD film was $\sim 240 \mathrm{~nm}$. Finally, $100 \mathrm{~nm} \mathrm{Au}$ was evaporated on $\mathrm{PbS}$ film to complete the device fabrication. The active device area $\left(9 \mathrm{~mm}^{2}\right)$ was defined by shadow mask. It is noted that majority of highefficiency $\mathrm{PbS}$ QDSCs reported so far were obtained based on small area $\left(<5 \mathrm{~mm}^{2}\right)$ which was almost half of our device area.

\subsection{Characterizations}

The $\mathrm{ZnO}$ films were investigated by X-ray diffraction (XRD) with $\mathrm{Cu} \mathrm{Ka}$ radiation (Philips, $\mathrm{X}$ pert pro MRD, Netherlands), UV-Vis absorption spectra (Cary, Lambda 950, America), Hall effect (Ecopia, HMS-5500, Korea), photoluminescence (PL, LabRAM HR800, France), and X-ray photoelectron spectroscopy (XPS, EDAX Inc. Genesis, America). The device cross-section was obtained from using scanning electron microscopy (FEI Nova 450, America). The $J-V$ characteristics were measured by a Keithley 2400 source unit with Xenon lamp (Newport, 3A solar simulator, 94023A-U, Germany) as the light source with simulated air mass (AM) $1.5 \mathrm{G}$ irradiation at $100 \mathrm{~mW}$ $\mathrm{cm}^{-2}$. The external quantum efficiency (EQE) measurements were taken by a home-made setup containing a Keithley 2400 Source Measure unit and Newport monochromator. The output power was also calibrated by $\mathrm{Si}$ photodetectors. The work function of various $\mathrm{ZnO}$ films was measured by using a Scanning Kelvin Probe microscopy (SKPM, UHV-KP, KP technology, Britain) in air at dark condition. The $C-V$ measurements were acquired with an Agilent 4200A at a frequency of $10 \mathrm{kHz}$ and AC signal of $50 \mathrm{mV}$, scanning from -1 to $+0.6 \mathrm{~V}$, with a step size of $50 \mathrm{mV}$. The EIS of the QD SCs was performed on an electrochemical workstation (Autolab PGTSAT302N, Metrohm Autolab, Utrecht, Netherlands) in the dark with the frequency ranging from 0.1 to $10^{6} \mathrm{~Hz}$.

\section{Results and Discussion}

As a window layer, the optical transmittance determined the light response of absorber layer in solar cells. Considering the varied window layer thickness effect, three typical thicknesses of 30,90 , and $150 \mathrm{~nm}$ were prepared to investigate the thickness-dependent optoelectronic properties. Figure 1a shows the UV-Vis transmittance spectra of three typical $\mathrm{ZnO}$ layers. As the $\mathrm{ZnO}$ film thickness increases, the onset absorption is red shift. The optical band gaps $\left(E_{\mathrm{g}}\right)$ extracted from Tauc plots [32] (inset of Fig. 1a) are 3.35, 3.26, and $3.18 \mathrm{eV}$, respectively. From the onset of absorption spectra, there are tail states extending into the bandgap (inset), which may have arisen from impurities and defects at grain boundaries [33-35]. Interestingly, the increased thickness would increase the losses of light absorption, while it simultaneously reduces the densities of tail states, which would be explained in the latter part by different thermal treatment times. Therefore, it is necessary to optimize the $\mathrm{ZnO}$ film thickness to balance the transmittance and the density of tail states. XRD patterns (Fig. 1b) for different thicknesses of $\mathrm{ZnO}$ films indicate that the crystallinity with wurtzite structure could be enhanced as the thickness increased [15, 36]. Moreover, the $c$-axis oriented (002) intensity of thicker $\mathrm{ZnO}$ film is stronger than the thinner ones, demonstrating the orientation growth which may improve the carrier transport mobility [37].

The thickness-dependent electrical properties were characterized by Hall measurement (Fig. S1b) or field-effect transistors (FET) [38] (Fig. S1c-d). It is worth noting that electrical properties of the thinner $\mathrm{ZnO}(30 \mathrm{~nm})$ film was too insulating to be tested by Hall measurement, and thus we converted to FET testing. The extracted electrical results are listed in Table 1 . The carrier mobility of thicker $\mathrm{ZnO}$ films increases one order more than the thinner ones. And the corresponding carrier concentrations increase by two orders as the film thickness increased. The higher carrier mobility of thick film can be explained with the decreased concentration of grain boundaries in thicker films [39].

Figure 2a shows the schematic device structure of $\mathrm{ZnO}$ $\mathrm{PbS}$ QD SCs consisting of n-type $\mathrm{ZnO}$ layer and p-type $\mathrm{PbS}$ QD absorber layer. The bandgap of QDs used in this work is $1.39 \mathrm{eV}$ (Fig. S1a). The thickness of $\mathrm{ZnO}$ and $\mathrm{PbS}$ films was strictly confirmed by scanning electron microscopy (SEM) characterization. Figure $2 b$ shows the sharp contrast from different functional layers in cross-section image.

The $J-V$ characteristics of $\mathrm{ZnO}-\mathrm{PbS}$ QD SCs with three representative thicknesses $(30,90$, and $150 \mathrm{~nm})$ are shown in Fig. 2c, where the corresponding $\mathrm{ZnO}$ film layers are denoted as $\mathrm{C}-\mathrm{ZnO}$ (control $\mathrm{ZnO}$ layer, $30 \mathrm{~nm}$ ), O-ZnO (optimized $\mathrm{ZnO}$ layer, $90 \mathrm{~nm}$ ), and $\mathrm{T}-\mathrm{ZnO}$ (thicker $\mathrm{ZnO}$ layer, $150 \mathrm{~nm}$ ). The control devices with $\mathrm{C}-\mathrm{ZnO}$ exhibit a $J_{\text {sc }}$ of $17.42 \mathrm{~mA} \mathrm{~cm}^{-2}$, a $V_{\text {oc }}$ of $0.51 \mathrm{~V}$, and a $F F$ of $48 \%$, leading to a $P C E$ of $4.26 \%$. According to the Site's method [40], the series resistance $\left(R_{\mathrm{S}}\right)$ and shunt resistance $\left(R_{\mathrm{sh}}\right)$ are 7.6 and $160.56 \Omega \mathrm{cm}^{2}$, respectively. As the $\mathrm{ZnO}$ layer thickness increases, the $P C E$ of CQD SCs is firstly 

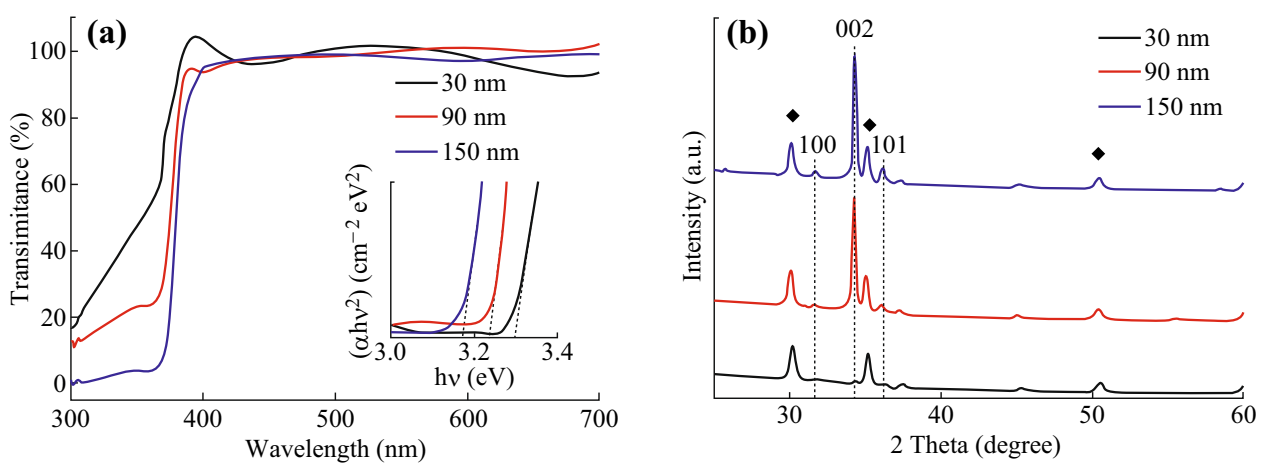

Fig. 1 a Transmittance spectra (Inset: the Tauc plots of various thickness ZnO layers). b XRD patterns of ZnO films on ITO/glass substrate. ITO peaks are marked by black diamonds and $\mathrm{ZnO}$ peaks are identified by their Miller indices

Table 1 Thickness-dependent electrical properties for varied thickness of $\mathrm{ZnO}$ layer

\begin{tabular}{llrr}
\hline Thickness of ZnO film (nm) & Carrier concentration $\left(\mathrm{cm}^{-3}\right)$ & Mobility $\left(\mathrm{cm}^{2} \mathrm{v}^{-1} \mathrm{~s}^{-1}\right)$ & Conductivity $\left(\mathrm{S} \mathrm{cm}{ }^{-1}\right)$ \\
\hline 30 & $1.05 \times 10^{16}$ & $8.7 \times 10^{-3 \mathrm{a}}$ & $2.25 \times 10^{-3}$ \\
90 & $1.02 \times 10^{18}$ & $3.64 \times 10^{-1 \mathrm{~b}}$ & $5.92 \times 10^{-2}$ \\
150 & $1.70 \times 10^{18}$ & $1.04 \times 10^{-1 \mathrm{~b}}$ & $2.83 \times 10^{-2}$ \\
\hline
\end{tabular}

a The values are extracted from FET measurements

b The data are obtained from Hall measurements

(a)
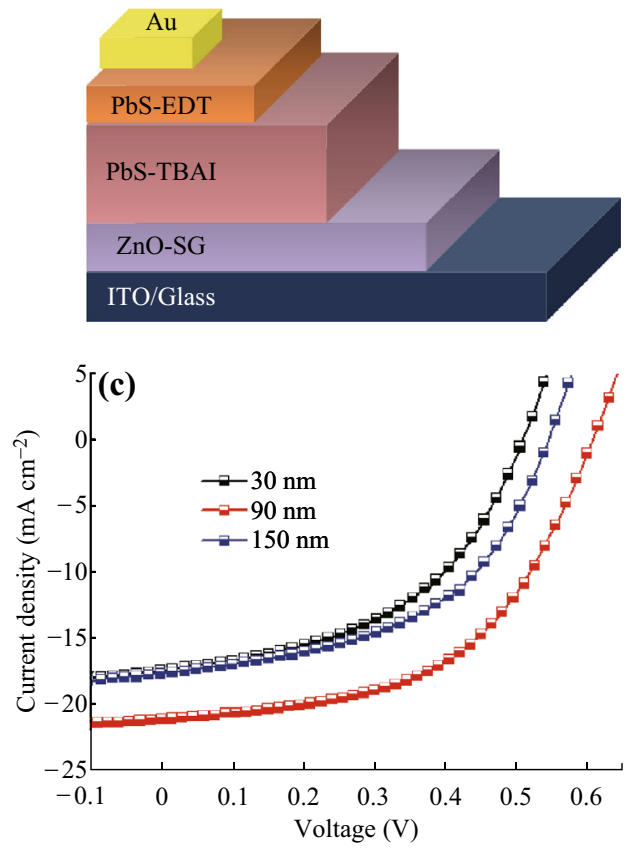

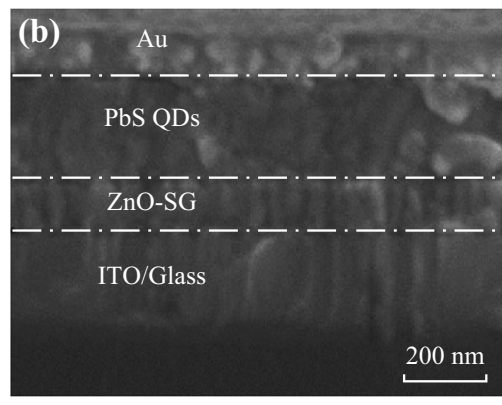

(d)

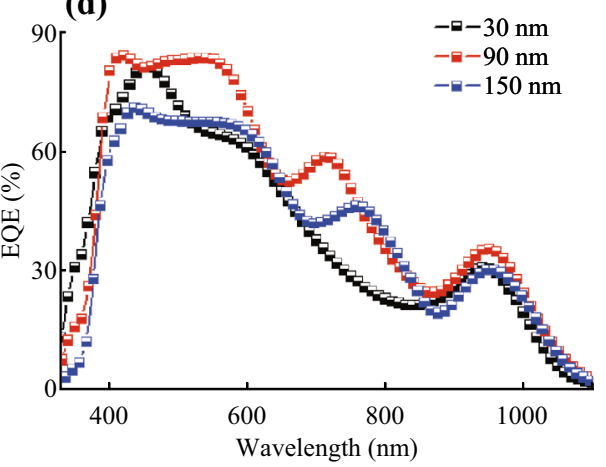

Fig. 2 a Schematic device structure. b Cross-section SEM image of ZnO-PbS QD device. c Representative $J-V$ characteristics. d $E Q E$ curves of devices with various $\mathrm{ZnO}$ film thicknesses

increased and the champion device $(\mathrm{O}-\mathrm{ZnO})$ reaches $6.7 \%$ with a $J_{\mathrm{sc}}$ of $21.08 \mathrm{~mA} \mathrm{~cm}{ }^{-2}$ when the thickness of $\mathrm{ZnO}$ films is $90 \mathrm{~nm}$. Further increase would lead to the deterioration of $P C E$. The detailed $\mathrm{ZnO}$ film and device parameters are summarized in Table 2. From the comparison between them, all the parameters of $\mathrm{O}-\mathrm{ZnO}$ are 
Table 2 Device performance parameters obtained from Fig. 2c

\begin{tabular}{lllllllll}
\hline Device & $\mu\left(\mathrm{cm}^{2}\left(\mathrm{v} \mathrm{s}^{-1}\right)\right.$ & $V_{\mathrm{oc}}(\mathrm{V})$ & $\left.J_{\mathrm{sc}}(\mathrm{mA} \mathrm{cm})^{-2}\right)$ & $\mathrm{FF}(\%)$ & $\eta(\%)$ & $R_{\mathrm{s}}\left(\Omega \mathrm{cm}^{2}\right)$ & $R_{\mathrm{sh}}\left(\Omega \mathrm{cm}^{2}\right)$ & $J_{0}\left(\mathrm{~mA} \mathrm{~cm}^{-2}\right)$ \\
\hline 30-nm (C-ZnO) SCs & $8.7^{\mathrm{a}}$ & 0.51 & 17.42 & 47.89 & 4.26 & 7.6 & 160.58 & $1.3 \times 10^{-3}$ \\
90-nm (O-ZnO) SCs & $3.64 \times 10^{-1} \mathrm{~b}$ & 0.60 & 21.08 & 52.79 & 6.73 & 2.6 & 273.2 & $1.4 \times 10^{-4}$ \\
150-nm (T-ZnO) SCs & $1.04 \times 10^{-1 \mathrm{~b}}$ & 0.54 & 17.63 & 49.87 & 4.78 & 8.8 & 151.47 & $7.8 \times 10^{-4}$ \\
\hline
\end{tabular}

a The values are extracted from FET measurements

b The data are obtained from Hall measurements
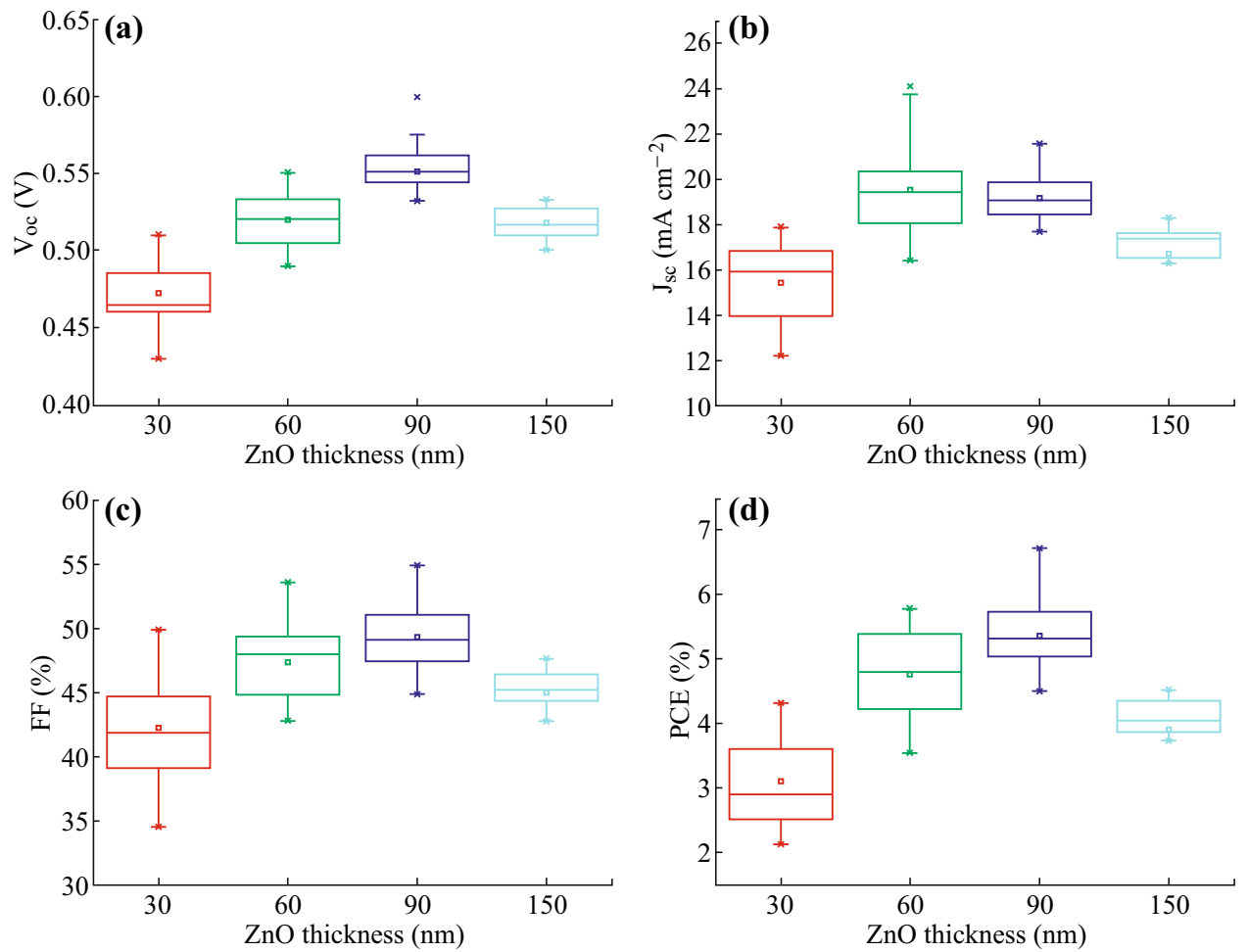

Fig. 3 Statistics of device performance using various thicknesses of $\mathrm{ZnO}$ window layer $(x=30,60,90$, and $150 \mathrm{~nm})$ : a $V_{\mathrm{oc}}, \mathbf{b} J_{\mathrm{sc}}, \mathbf{c} F F$, d $P C E$. The solid squares represent the average values, and the horizontal lines in the box denote the 25th, 50th, and 75th percentile values

simultaneously improved. In order to guarantee the credible device performance, sixteen to twenty devices of each type were fabricated and their parameter distribution is shown in Fig. 3. Their statistical deviations are small, and thus our improvement is reliable.

To study the origin of $J_{\mathrm{sc}}$ improvement, EQE spectra of three types of $\mathrm{ZnO}$ film-based devices are shown in Fig. 2d. There are three characteristic regions from $E Q E$ comparison. In ultra-violet region $(300-400 \mathrm{~nm})$, the response in control devices is highest, which agreed well with aforementioned absorption measurement results of $\mathrm{ZnO}$ films. Thus, the response loss for devices based on $\mathrm{O}-\mathrm{ZnO}$ and $\mathrm{T}-\mathrm{ZnO}$ film is mainly caused by window layer absorption. In visible region $(500-800 \mathrm{~nm}), \mathrm{O}-\mathrm{ZnO}$ devices demonstrate higher and broader response. This result demonstrates that $\mathrm{O}-\mathrm{ZnO}$ devices could more efficiently extract electrons from $\mathrm{PbS}$ QD layers. In infrared region, all three EQE values are similar among these devices, which confirm the efficient back field in PbS-TBAI/PbSEDT device structure [14]. To investigate the contribution of $J_{\mathrm{sc}}$ for various $\mathrm{ZnO}-\mathrm{PbS}$ devices, Fig. S3a shows the integrated short-currents for $\mathrm{C}-\mathrm{ZnO}$ and $\mathrm{O}-\mathrm{ZnO}$ devices. Compared with $\mathrm{C}-\mathrm{ZnO}$ film devices, although a loss of light absorption is found in first region (Region I, UV spectrum) for $\mathrm{O}-\mathrm{ZnO}$ device, the more contributions of short-currents can be obtained from second and third regions (Region II and III, visible and infrared regions). The current density variations corresponding to Region IIII are $0.25,2.21$, and $1.09 \mathrm{~mA} \mathrm{~cm}^{-2}$, respectively. Consequently, the $\mathrm{O}-\mathrm{ZnO}$ devices could more efficiently convert visible and infrared spectra into photocurrent. On the other hand, UV spectra energy only takes $4 \%$ while the visible and infrared spectra energy takes more than $90 \%$ in solar spectra energy distribution. Based on the above 

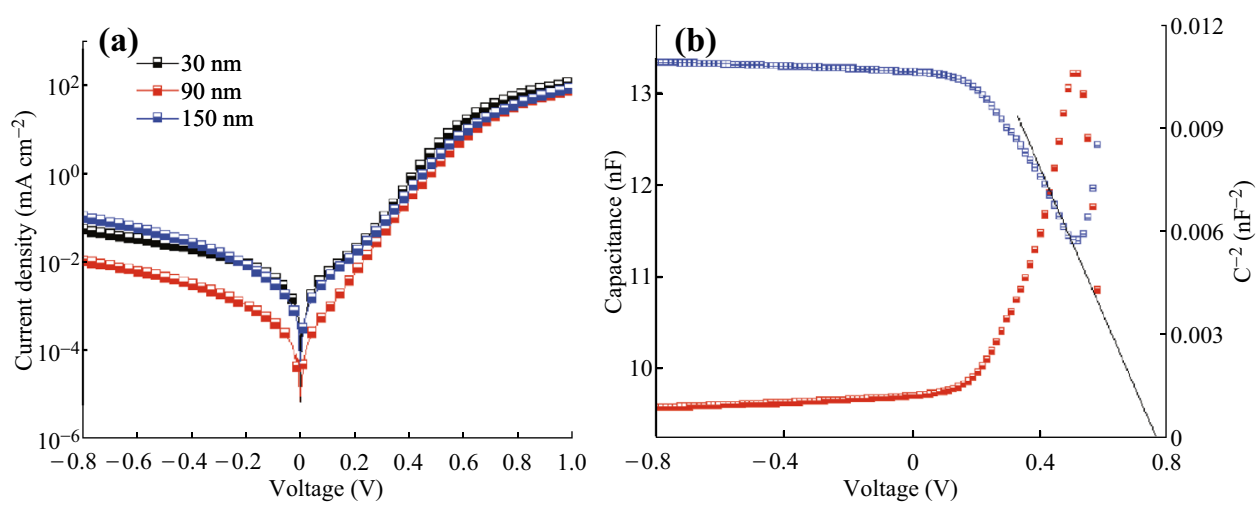

(c)

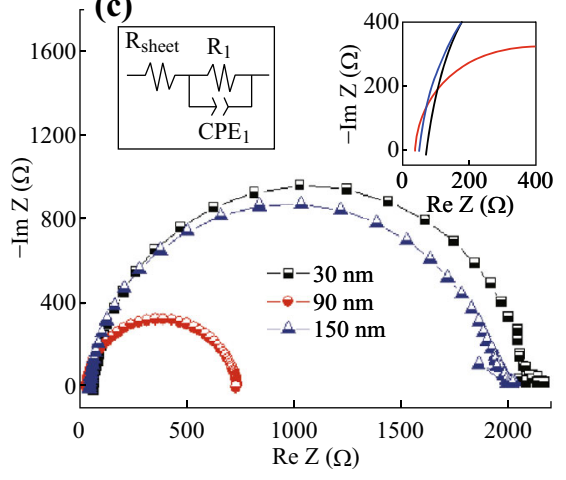

Fig. 4 a Logarithmic plots of dark $J-V$ characteristics. b Capacitance-voltage measurement results and Mott-Schottky plots of ZnO-PbS QD $\mathrm{SC}$-based $\mathrm{O}-\mathrm{ZnO}$, the red and blue curves are represented $C-V$ and $\mathrm{C}^{-2}-\mathrm{V}$ evolutions, respectively. $\mathbf{c}$ The AC impedance spectroscopy of the QD $\mathrm{SCs}$ with various $\mathrm{ZnO}$ films. Insets indicate the equivalent circuit model (left) and intercept (right) with the horizontal axis, respectively

analysis, the improved quantum efficiency in visible and infrared regions is the main contribution to achieve the higher short-currents of $\mathrm{ZnO}-\mathrm{PbS}$ SCs.

In order to gain the physical origins of the improved parameters $\left(V_{\mathrm{oc}}, J_{\mathrm{sc}}, F F\right)$ in $\mathrm{O}-\mathrm{ZnO}$ device, further characterizations were carried out for various thicknesses of $\mathrm{ZnO}$ film and their corresponding devices. Figure $4 \mathrm{a}$ shows the logarithmic plots of dark $J-V$ curves. The reverse saturation current is greatly suppressed in $\mathrm{O}-\mathrm{ZnO}$ devices. The lower $J_{0}$ value $\left(2.18 \times 10^{-4} \mathrm{~mA} \mathrm{~cm}^{-2}\right)$ demonstrates the superior heterojunction quality which also can be confirmed from the higher $R_{\text {sh }}$ in Fig. S2b. It is known that $V_{\text {oc }}$ depends strongly on the ideal factor $(n)$ and reversed saturation current density $\left(J_{0}\right)$, described by Eq. 1 [41].

$V_{\mathrm{OC}}=\frac{n K T}{q}\left(\ln \frac{J_{\mathrm{SC}}}{J_{0}}+1\right)$,

where $q$ is the elementary charge. According to Eq. 1, $\mathrm{O}-\mathrm{ZnO}$ device has higher $V_{\mathrm{oc}}$ than others due to its lower reverse saturation current and higher $J_{\mathrm{sc}}$. For the heterojunction analysis, the work function $\left(W_{\mathrm{f}}\right)$ of three kinds of window layers was measured from the SKPM results (Fig. S3b). With the increase of $\mathrm{ZnO}$ film thickness, the $W_{\mathrm{f}}$ became shallower which could help to improve the $V_{\text {oc }}$ of corresponding devices [42].
Because of the higher $J_{\mathrm{sc}}$, we further analyzed the depletion region of $\mathrm{ZnO} / \mathrm{PbS} \mathrm{QD} \mathrm{SCs}$ by capacitance versus voltage $(C-V)$ measurements as shown in Fig. $4 \mathrm{~b}$ and $\mathrm{S} 3 \mathrm{~d}$. The built-in voltage $\left(V_{\mathrm{bi}}\right)$ is extracted from the intercept of $1 / \mathrm{C}^{2}$ curve on horizontal axis. The dopant concentration $\left(N_{\mathrm{A}}\right)$ for $\mathrm{PbS}$ QD layer could be extracted from the slope of the Mott-Schottky plot from Eq. 2 $[43,44]$,

$N_{\mathrm{A}}=\frac{2}{A^{2} q \varepsilon_{\mathrm{QD}} \varepsilon_{0} \frac{\mathrm{d}}{\mathrm{d} V}\left(\frac{1}{C^{2}}\right)}$,

where $\varepsilon_{0}$ is the dielectric constant of vacuum, $\varepsilon_{\mathrm{QD}}$ is the QD dielectric constant extracted as shown in Fig. S3c, and $A$ corresponds to the device active area. Substituting all the parameters in Eq. 2, the carrier concentration of $\mathrm{PbS}$ QD layer is extracted as $4.79 \times 10^{16} \mathrm{~cm}^{-3}$, which is in accordance with reported values of TBAI-treated PbS QD films [12]. Utilizing the above carrier concentration, we can calculate the depleted width of $\mathrm{QD}$ layer $\left(W_{\mathrm{PbS}}\right)$ at zero bias according to Eq. 3 [44].

$W_{\mathrm{PbS}}=\frac{1}{N_{\mathrm{A}}}\left[\frac{2 \varepsilon_{\mathrm{QD}} \varepsilon_{0}}{q\left(\frac{1}{N_{\mathrm{D}}}+\frac{1}{N_{\mathrm{A}}}\right)} V_{\mathrm{bi}}\right]^{\frac{1}{2}}$ 
where $N_{\mathrm{D}}$ is the carrier concentration of $\mathrm{ZnO}$ film, which is extracted by FET or Hall measurements as mentioned above (Table 1). The obtained parameters are summarized in Table 3 . The carrier concentration evolution with varied thickness is mainly attributed to our LBL sol-gel method. The thicker $\mathrm{ZnO}$ film faces longer thermal treatment time, inducing varied doping concentration [45, 46]. It is noteworthy that Mott-Schottky analysis in a Schottky junction or an abrupt heterojunction must be based on the premise, in which the carrier concentration of N-type layer must be much higher than that of p-type layer [47]. Therefore, the C-ZnO-based parameters could not meet the Mott-Schottky equation. Here we roughly estimate $W_{\mathrm{PbS}}$ according to the device based on $60 \mathrm{~nm} \mathrm{ZnO} \mathrm{film} \mathrm{(Table} \mathrm{S1)} \mathrm{and} \mathrm{Eq.} 4$ [48],

$N_{\mathrm{D}} \times W_{\mathrm{ZnO}}=N_{\mathrm{A}} \times W_{\mathrm{PbS}}$

The $W_{\mathrm{PbS}}$ for C-ZnO-based devices $(<151 \mathrm{~nm}$, referring to Table S1) is much narrower than the other two devices. The $W_{\mathrm{PbS}}$ for O-ZnO-based devices extends to $185 \mathrm{~nm}$ (Table 3 ). The higher carrier concentration of $\mathrm{ZnO}$ films could help to extend the $W_{\mathrm{PbS}}$ and enhance the electrical field resulting in the improvement of the charge-collection efficiency.

For $F F$ enhancement analysis, EIS was measured to investigate the interfacial properties. Figure 4c shows the Nyquist plots of varied thickness of $\mathrm{ZnO}$ film-based devices. Only one semicircle is obtained in these devices regardless of the $\mathrm{ZnO}$ film thickness. From their equivalent circuit diagrams and intercept with the horizontal axis, the O-ZnO-based devices extract a smaller series resistance. Thus, the higher $F F$ in O-ZnO PbS QDSCs is ascribed to the decreased $R_{\mathrm{s}}$ [26].

In addition, the window layer $\mathrm{ZnO}$ film itself also plays the key role in device performance. Photoluminescence (PL) spectra and X-ray photoelectron spectroscopy (XPS) reveal more details for its functionality. As shown in Fig. 5a, there are approximately two emission peaks in PL spectra. One is centered at $\sim 365 \mathrm{~nm}$ corresponding to band-edge emission, and the other broad one located at $\sim 530 \mathrm{~nm}$ is attributed to the oxygen vacancy $\left(V_{\mathrm{O}}\right)$ defectrelated emission [49-51]. It is clearly shown that the

Table 3 Device performance parameters extracted from the Mott-Schottky analysis

\begin{tabular}{lllllc}
\hline Devices & $V_{\text {bi }}(\mathrm{V})$ & $N_{\mathrm{D}}\left(\mathrm{cm}^{-3}\right)$ & $N_{\mathrm{A}}\left(\mathrm{cm}^{-3}\right)$ & $W_{\mathrm{D}, \mathrm{ZnO}}(\mathrm{nm})$ & $W_{\mathrm{PbS}}(\mathrm{nm})$ \\
\hline C-ZnO-PbS & - & $1.6 \times 10^{16}$ & $\sim 4 \times 10^{16}$ & $\leq 30$ & $<151$ \\
O-ZnO-PbS & 0.79 & $1.0 \times 10^{18}$ & $4.8 \times 10^{16}$ & 8.8 & 185 \\
T-ZnO-PbS & 0.76 & $1.7 \times 10^{18}$ & $4.5 \times 10^{16}$ & 5.1 & 190 \\
\hline
\end{tabular}
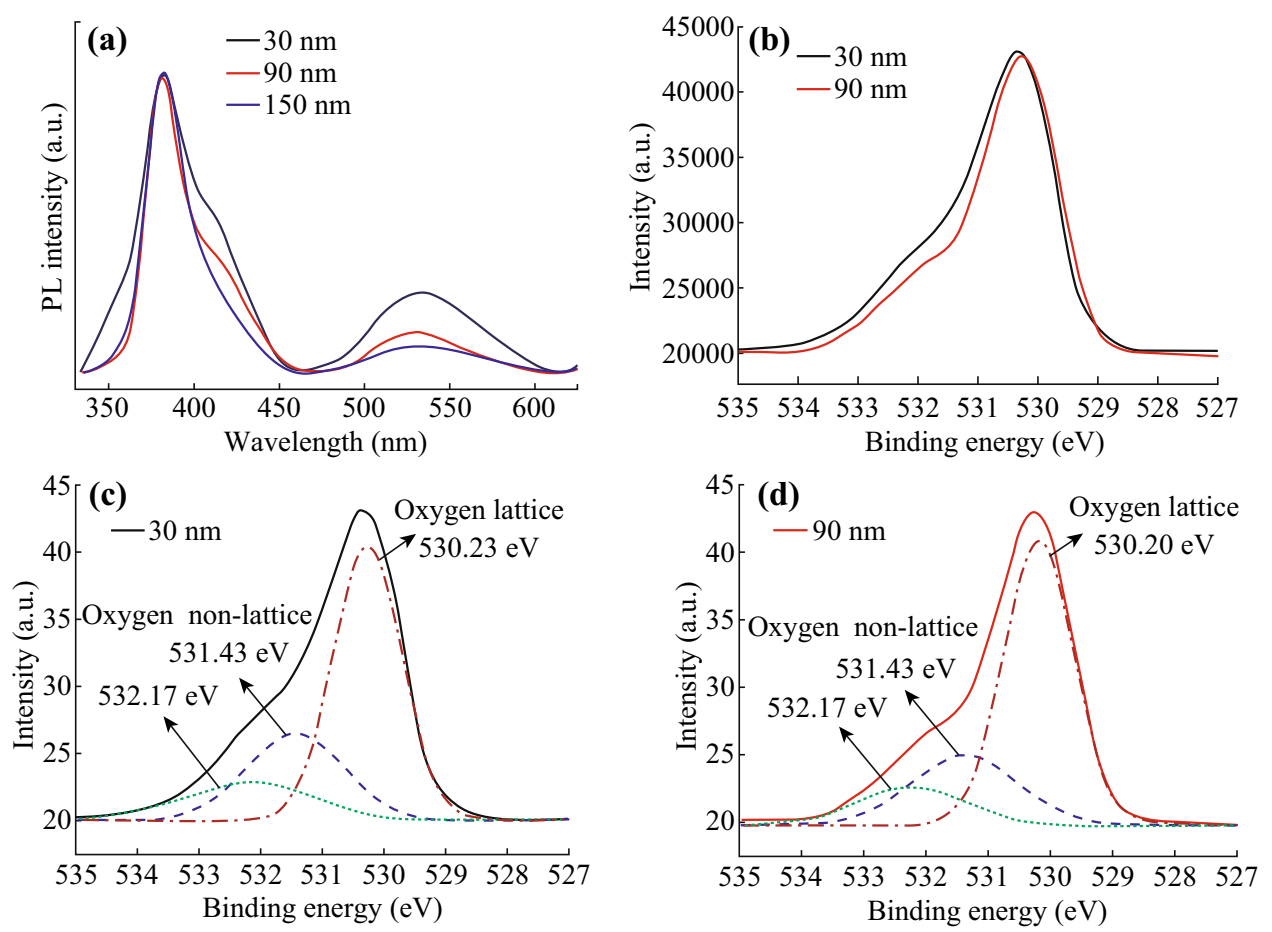

Fig. 5 a Steady-state normalized PL spectra of various ZnO layers excited at $325 \mathrm{~nm}$. b XPS survey spectra of the O1s core level of C-ZnO film $(30 \mathrm{~nm})$ and $\mathrm{O}-\mathrm{ZnO}(90 \mathrm{~nm})$. Deconvoluted XPS spectra of $\mathbf{c} \mathrm{C}-\mathrm{ZnO}$, and $\mathbf{d} \mathrm{O}-\mathrm{ZnO}$ 
visible emission is strongly suppressed in thicker film. Thus, the rich defects in C-ZnO-based devices may lead to the EQE losses within 500-600 nm region corresponding to the defect absorption [49]. As mentioned above, the depletion region is mainly located at $\mathrm{PbS}$ layers because $\mathrm{ZnO}$ has a higher carrier concentration $\left(10^{18} \mathrm{~cm}^{-3}\right)$ than that of PbS-CQDs $\left(10^{16}\right)$. With the help of built-in electric field in the depletion region, the separated carriers can be more efficient drift and collection than diffusion region. Thus, the effective passivation by annealing in thick $\mathrm{ZnO}$ film may be the crucial origin of the reduced charge recombination [52].

The XPS spectra provide more details in terms of the surface component of $\mathrm{ZnO}$. The O1s core level spectra of the $\mathrm{C}-\mathrm{ZnO}$ and $\mathrm{O}-\mathrm{ZnO}$ are shown in Fig. 5b. In general, the peak for $\mathrm{ZnO}$ are deconvoluted into three peaks: the lower-binding-energy peak $(530.2 \mathrm{eV})$ is associated with the oxygen atoms in a $\mathrm{ZnO}$ matrix, the higher-binding-energy peaks (532.17 and $531.43 \mathrm{eV}$ ) are attributed to the oxygen-deficient defects such as oxygen vacancies and hydroxyl $\mathrm{OH}$ groups (Fig. 5c, d) [37]. After increasing the thickness (annealing time), the relative intensities of higher-binding-energy components decreased (Fig. 5b, d), suggesting that the oxygen-deficient defects in the $\mathrm{ZnO}$ films are suppressed. These results, together with PL analyses, indicate that the thicker film could help to passivate window layer defects.

In consequence, the appropriate thickness of $\mathrm{ZnO}$ films and suitable annealing time suppressed the interfacial charge recombination at the $\mathrm{ZnO}-\mathrm{PbS}$ interface to enhance the charge separation at heterojunctions. It could also improve the $\mathrm{ZnO}$ films dopant concentration, which may be caused by the interstitial $\mathrm{Zn}_{I}$ rather than $\mathrm{V}_{\mathrm{O}}$ [53]. The heavier doping of $\mathrm{ZnO}$ layer could help to extend depletion width in QD layer leading to a broader EQE. Thus, charge extraction properties of $\mathrm{C}-\mathrm{ZnO}$ and $\mathrm{O}-\mathrm{ZnO}$ devices can be

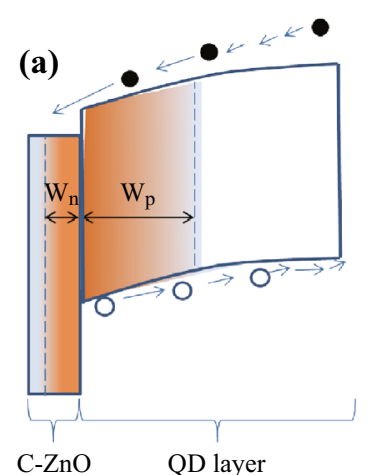

(n)

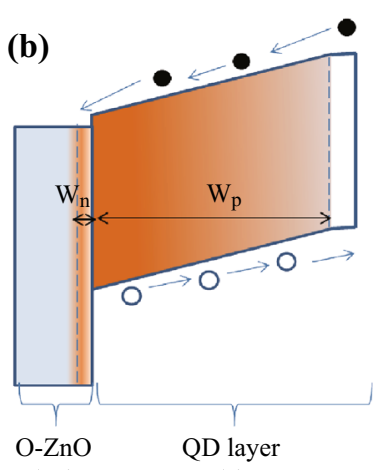

(p)
Fig. 6 Schematic depletion region evolution as the effect of $\mathrm{ZnO}$ layer. a C- $\mathrm{ZnO}-\mathrm{PbS}$ heterojunction, and $\mathbf{b} \mathrm{O}-\mathrm{ZnO}-\mathrm{PbS}$ heterojunction QDSCs. $W_{\mathrm{n}}$ and $W_{\mathrm{p}}$ are the depletion region widths of window and absorber layers, respectively schematically described as shown in Fig. 6a, b. $W_{\mathrm{n}}$ and $W_{\mathrm{p}}$ represent the depletion region widths in the $\mathrm{ZnO}$ layer and QD layer, respectively. The increased doping concentration of O-ZnO could extend the $W_{\mathrm{p}}$, suppress the recombination, and improve the short-current density.

\section{Conclusions}

In the present work, we have successfully demonstrated an obvious improvement in the performance of $\mathrm{ZnO}-\mathrm{PbS} \mathrm{QD}$ SCs via optimizing the window layer. The optimized $\mathrm{O}-\mathrm{ZnO}$ window layer-based $\mathrm{PbS} \mathrm{QD}$ SCs showed an enhanced $P C E$ of $58 \%$ compared with control devices. The physical mechanism for enhanced parameters $\left(V_{\mathrm{oc}}, J_{\mathrm{sc}}\right.$, and $F F)$ was also systematically illustrated. It demonstrated that the $\mathrm{O}-\mathrm{ZnO}$ could reduce the surface defects, extend the depleted width in heterojunction, and align with energy band of absorber layer. The above effects could be conveniently implemented by optimizing the $\mathrm{ZnO}$ film thickness and its parasitic thermal treatment. The present simple and reliable optimizing strategy may provide a viable reference for depleted-heterojunction solar cells.

Acknowledgements This work was financially supported by the National Natural Science Foundation of China (61306137, 51602114), the Research Fund for the Doctoral Program of Higher Education (20130142120075) and the Fundamental Research Funds for the Central Universities (HUST:2016YXMS032), the GuangdongHong Kong joint innovation project (Grant No. 2016A050503012), and the Guangdong Natural Science Funds for Distinguished Young Scholars (Grant No. 2015A030306044). The authors also thank Testing Center of HUST and the Center for Nanoscale Characterization and Devices, Wuhan National Laboratory for Optoelectronics (WNLO) for facility access.

Open Access This article is distributed under the terms of the Creative Commons Attribution 4.0 International License (http://crea tivecommons.org/licenses/by/4.0/), which permits unrestricted use, distribution, and reproduction in any medium, provided you give appropriate credit to the original author(s) and the source, provide a link to the Creative Commons license, and indicate if changes were made.

\section{References}

1. O.E. Semonin, J.M. Luther, S. Choi, H.-Y. Chen, J. Gao, A.J. Nozik, M.C. Beard, Peak external photocurrent quantum efficiency exceeding $100 \%$ via MEG in a quantum dot solar cell. Science 334(6062), 1530-1533 (2011). doi:10.1126/science. 1209845

2. M. Graetzel, R.A.J. Janssen, D.B. Mitzi, E.H. Sargent, Materials interface engineering for solution-processed photovoltaics. Nature 488(7411), 304-312 (2012). doi:10.1038/nature11476

3. C.H.M. Chuang, P.R. Brown, V. Bulovic, M.G. Bawendi, Improved performance and stability in quantum dot solar cells through band alignment engineering. Nat. Mater. 13(8), 796-801 (2014). doi:10.1038/nmat3984 
4. S.A. McDonald, G. Konstantatos, S. Zhang, P.W. Cyr, E.J.D. Klem, L. Levina, E.H. Sargent, Solution-processed PbS quantum dot infrared photodetectors and photovoltaics. Nat. Mater. 4(2), 138-142 (2005). doi:10.1038/nmat1299

5. G. Konstantatos, E.H. Sargent, PbS colloidal quantum dot photoconductive photodetectors: transport, traps, and gain. Appl. Phys. Lett. 91(17), 173505 (2007). doi:10.1063/1.2800805

6. K. Qiao, H. Deng, X. Yang, D. Dong, M. Li, L. Hu, H. Liu, H. Song, J. Tang, Spectra-selective PbS quantum dot infrared photodetectors. Nanoscale 8(13), 7137-7143 (2016). doi:10.1039/ C5NR09069E

7. G. Konstantatos, C. Huang, L. Levina, Z. Lu, E.H. Sargent, Efficient infrared electroluminescent devices using solution-processed colloidal quantum dots. Adv. Funct. Mater. 15(11), 1865-1869 (2005). doi:10.1002/adfm.200500379

8. L. Sun, J.J. Choi, D. Stachnik, A.C. Bartnik, B.-R. Hyun, G.G. Malliaras, T. Hanrath, F.W. Wise, Bright infrared quantum-dot light-emitting diodes through inter-dot spacing control. Nat. Nanotechnol. 7(6), 369-373 (2012). doi:10.1038/nnano.2012.63

9. H. Lee, H.C. Leventis, S.-J. Moon, P. Chen, S. Ito et al., PbS and CdS quantum dot-sensitized solid-state solar cells: "old concepts, new results". Adv. Funct. Mater. 19(17), 2735-2742 (2009). doi:10.1002/adfm.200900081

10. G.I. Koleilat, L. Levina, H. Shukla, S.H. Myrskog, S. Hinds, A.G. Pattantyus-Abraham, E.H. Sargent, Efficient, stable infrared photovoltaics based on solution-cast colloidal quantum dots. ACS Nano 2(5), 833-840 (2008). doi:10.1021/nn800093v

11. J. Tang, L. Brzozowski, D.A.R. Barkhouse, X. Wang, R. Debnath et al., Quantum dot photovoltaics in the extreme quantum confinement regime: the surface-chemical origins of exceptional airand light-stability. ACS Nano 4(2), 869-878 (2010). doi:10.1021/ $\mathrm{nn} 901564 \mathrm{q}$

12. X. Lan, O. Voznyy, A. Kiani, F.P. Garcia de Arquer, A.S. Abbas et al., Passivation using molecular halides increases quantum dot solar cell performance. Adv. Mater. 28(2), 299-304 (2016). doi:10.1002/adma.201503657

13. M. Liu, F.P. de Arquer, Y. Li, X. Lan, G.H. Kim et al., Doublesided junctions enable high-performance colloidal-quantum-dot photovoltaics. Adv. Mater. 28(21), 4142-4148 (2016). doi:10. 1002/adma.201506213

14. C.H. Chuang, P.R. Brown, V. Bulovic, M.G. Bawendi, Improved performance and stability in quantum dot solar cells through band alignment engineering. Nat. Mater. 13(8), 796-801 (2014). doi:10.1038/nmat3984

15. J. Luo, X. Dai, S. Bai, Y. Jin, Z. Ye, X. Guo, Ligand exchange of colloidal $\mathrm{ZnO}$ nanocrystals from the high temperature and nonaqueous approach. Nano-Micro Lett. 5(4), 274-280 (2013). doi:10.1007/BF03353758

16. G.H. Kim, F.P. Garcia de Arquer, Y.J. Yoon, X. Lan, M. Liu et al., High-efficiency colloidal quantum dot photovoltaics via robust self-assembled monolayers. Nano Lett. 15(11), 7691-7696 (2015). doi:10.1021/acs.nanolett.5b03677

17. Z. Yang, A. Janmohamed, X. Lan, F.P. Garcia de Arquer, O. Voznyy et al., Colloidal quantum dot photovoltaics enhanced by perovskite shelling. Nano Lett. 15(11), 7539-7543 (2015). doi:10.1021/acs.nanolett.5b03271

18. S. Bai, Z. Wu, X. Xu, Y. Jin, B. Sun et al., Inverted organic solar cells based on aqueous processed $\mathrm{ZnO}$ interlayers at low temperature. Appl. Phys. Lett. 100(20), 203906 (2012). doi:10.1063/ 1.4719201

19. L.K. Jagadamma, M. Abdelsamie, A. El Labban, E. Aresu, G.O. Ngongang Ndjawa, D.H. Anjum, D. Cha, P.M. Beaujuge, A. Amassian, Efficient inverted bulk-heterojunction solar cells from low-temperature processing of amorphous $\mathrm{ZnO}$ buffer layers. J. Mater. Chem. A 2(33), 13321-13331 (2014). doi:10.1039/ C4TA02276A
20. J. You, C.-C. Chen, L. Dou, S. Murase, H.-S. Duan et al., Metal oxide nanoparticles as an electron-transport layer in high-performance and stable inverted polymer solar cells. Adv. Mater. 24(38), 5267-5272 (2012). doi:10.1002/adma.201201958

21. E.A. Manor, T. Katz, F.C. Tromholt, Krebs, Enhancing functionality of $\mathrm{ZnO}$ hole blocking layer in organic photovoltaics. Sol. Energy Mater. Sol. Cells 98, 491-493 (2012). doi:10.1016/j. solmat.2011.11.026

22. C.E. Small, S. Chen, J. Subbiah, C.M. Amb, S.-W. Tsang, T.-H. Lai, J.R. Reynolds, F. So, High-efficiency inverted dithienogermole-thienopyrrolodione- based polymer solar cells. Nat. Photon. 6(2), 115-120 (2012). doi:10.1038/nphoton.2011.317

23. L. Guo, S. Yang, C. Yang, P. Yu, J. Wang, W. Ge, G.K.L. Wong, Highly monodisperse polymer-capped $\mathrm{ZnO}$ nanoparticles: preparation and optical properties. Appl. Phys. Lett. 76(20), 2901-2903 (2000). doi:10.1063/1.126511

24. H. Zhang, R.C. Shallcross, N. Li, T. Stubhan, Y. Hou, W. Chen, T. Ameri, M. Turbiez, N.R. Armstrong, C.J. Brabec, Overcoming electrode-induced losses in organic solar cells by tailoring a quasi-ohmic contact to fullerenes via solution-processed alkali hydroxide layers. Adv. Energy Mater. 6(9), 1502195 (2016). doi:10.1002/aenm.201502195

25. B.R. Lee, E.D. Jung, Y.S. Nam, M. Jung, J.S. Park et al., Aminebased polar solvent treatment for highly efficient inverted polymer solar cells. Adv. Mater. 26(3), 494-500 (2014). doi:10.1002/ adma.201302991

26. R. Azmi, H. Aqoma, W.T. Hadmojo, J.-M. Yun, S. Yoon, K. Kim, Y.R. Do, S.-H. Oh, S.-Y. Jang, Low-temperature-processed $9 \%$ colloidal quantum dot photovoltaic devices through interfacial management of p-n heterojunction. Adv. Energy Mater. 6(8), 1502146 (2016). doi:10.1002/aenm.201502146

27. S. Nho, G. Baek, S. Park, B.R. Lee, M.J. Cha et al., Highly efficient inverted bulk-heterojunction solar cells with a gradiently-doped $\mathrm{ZnO}$ layer. Energy Environ. Sci. 9(1), 240-246 (2016). doi:10.1039/C5EE03045E

28. S. Kwon, K.-G. Lim, M. Shim, H.C. Moon, J. Park et al., Airstable inverted structure of hybrid solar cells using a cesiumdoped $\mathrm{ZnO}$ electron transport layer prepared by a sol-gel process. J. Mater. Chem. A 1(38), 11802-11808 (2013). doi:10.1039/ c3ta12425h

29. B.S. Ong, C. Li, Y. Li, Y. Wu, R. Loutfy, Stable, solution-processed, high-mobility $\mathrm{ZnO}$ thin-film transistors. J. Am. Chem. Soc. 129(10), 2750-2751 (2007). doi:10.1021/ja068876e

30. B. Du Ahn, S.H. Oh, C.H. Lee, G.H. Kim, H.J. Kim, S.Y. Lee, Influence of thermal annealing ambient on Ga-doped $\mathrm{ZnO}$ thin films. J. Cryst. Growth 309(2), 128-133 (2007). doi:10.1016/j. jcrysgro.2007.09.014

31. L. Hu, D.-B. Li, L. Gao, H. Tan, C. Chen et al., Graphene doping improved device performance of $\mathrm{ZnMgO} / \mathrm{PbS}$ colloidal quantum dot photovoltaics. Adv. Funct. Mater. 26(12), 1899-1907 (2016). doi:10.1002/adfm.201505043

32. Y.S. Wang, P.J. Thomas, P. O'Brien, Optical properties of $\mathrm{ZnO}$ nanocrystals doped with $\mathrm{Cd}, \mathrm{Mg}, \mathrm{Mn}$, and Fe Ions. J. Phys. Chem. B 110(43), 21412-21415 (2006). doi:10.1021/jp0654415

33. H. Zeng, W. Cai, J. Hu, G. Duan, P. Liu, Y. Li, Violet photoluminescence from shell layer of $\mathrm{Zn} / \mathrm{ZnO}$ core-shell nanoparticles induced by laser ablation. Appl. Phys. Lett. 88(17), 171910 (2006). doi:10.1063/1.2196051

34. P.K. Nayak, J. Bisquert, D. Cahen, Assessing possibilities and limits for solar cells. Adv. Mater. 23(25), 2870-2876 (2011). doi:10.1002/adma.201100877

35. R.C. Rai, Analysis of the Urbach tails in absorption spectra of undoped $\mathrm{ZnO}$ thin films. J. Appl. Phys. 113(15), 153508 (2013). doi: $10.1063 / 1.4801900$

36. G.T. Ramesh, R. Gopikrishnan, K. Zhang, P. Ravichandran, S. Baluchamy et al., Synthesis, characterization and 
biocompatibility studies of zinc oxide $(\mathrm{ZnO})$ nanorods for biomedical application. Nano-Micro Lett. 2(1), 31-36 (2010). doi:10.1007/BF03353614

37. Y. Sun, J.H. Seo, C.J. Takacs, J. Seifter, A.J. Heeger, Inverted polymer solar cells integrated with a low-temperature-annealed sol-gel-derived $\mathrm{ZnO}$ Film as an electron transport layer. Adv. Mater. 23(14), 1679-1683 (2011). doi:10.1002/adma.201004301

38. D. Yang, B. Li, C. Hu, H. Deng, D. Dong, X. Yang, K. Qiao, S. Yuan, H. Song, Controllable growth orientation of SnS2 flakes for low-noise, high-photoswitching ratio, and ultrafast phototransistors. Adv. Opt. Mater. 4(3), 419-426 (2016). doi:10.1002/ adom.201500506

39. S. Christoulakis, M. Suchea, E. Koudoumas, M. Katharakis, N. Katsarakis, G. Kiriakidis, Thickness influence on surface morphology and ozone sensing properties of nanostructured $\mathrm{ZnO}$ transparent thin films grown by PLD. Appl. Surf. Sci. 252(15), 5351-5354 (2006). doi:10.1016/j.apsusc.2005.12.071

40. J.R. Sites, P.H. Mauk, Diode quality factor determination for thin-film solar cells. Solar Cells 27(1), 411-417 (1989). doi:10. 1016/0379-6787(89)90050-1

41. V. Nadenau, U. Rau, A. Jasenek, H. Schock, Electronic properties of $\mathrm{CuGaSe}_{2}$-based heterojunction solar cells. Part I. Transport analysis. J. Appl. Phys. 87(1), 584-593 (2000). doi:10.1063/1. 371903

42. P. Schilinsky, C. Waldauf, J. Hauch, C.J. Brabec, Simulation of light intensity dependent current characteristics of polymer solar cells. J. Appl. Phys. 95(5), 2816-2819 (2004). doi:10.1063/1. 1646435

43. P.R. Brown, R.R. Lunt, N. Zhao, T.P. Osedach, D.D. Wanger, L.Y. Chang, M.G. Bawendi, V. Bulovic, Improved current extraction from $\mathrm{ZnO} / \mathrm{PbS}$ quantum dot heterojunction photovoltaics using a $\mathrm{MoO}_{3}$ interfacial layer. Nano Lett. 11(7), 2955-2961 (2011). doi: $10.1021 / \mathrm{nl} 201472 \mathrm{u}$

44. S.M. Willis, C. Cheng, H.E. Assender, A.A. Watt, The transitional heterojunction behavior of $\mathrm{PbS} / \mathrm{ZnO}$ colloidal quantum dot solar cells. Nano Lett. 12(3), 1522-1526 (2012). doi:10.1021/ nl204323j
45. L.H. Quang, S.J. Chua, K. Ping Loh, E. Fitzgerald, The effect of post-annealing treatment on photoluminescence of $\mathrm{ZnO}$ nanorods prepared by hydrothermal synthesis. J. Cryst. Growth 287(1), 157-161 (2006). doi:10.1016/j.jcrysgro.2005.10.060

46. Y.G. Wang, S.P. Lau, H.W. Lee, S.F. Yu, B.K. Tay, X.H. Zhang, H.H. Hng, Photoluminescence study of $\mathrm{ZnO}$ films prepared by thermal oxidation of $\mathrm{Zn}$ metallic films in air. J. Appl. Phys. 94(1), 354-358 (2003). doi:10.1063/1.1577819

47. L.Y. Chang, R.R. Lunt, P.R. Brown, V. Bulovic, M.G. Bawendi, Low-temperature solution-processed solar cells based on $\mathrm{PbS}$ colloidal quantum dot/CdS heterojunctions. Nano Lett. 13(3), 994-999 (2013). doi:10.1021/n13041417

48. H. Lawrence, R.M. Warner, Diffused junction depletion layer calculations. Bell Syst. Tech. J. 39(2), 389-430 (1960). doi:10. 1002/j.1538-7305.1960.tb01607.x

49. T. Prasada Rao, G.K. Goswami, K.K. Nanda, Detailed understanding of the excitation-intensity dependent photoluminescence of $\mathrm{ZnO}$ materials: role of defects. J. Appl. Phys. 115(21), 213513 (2014). doi:10.1063/1.4881779

50. S. Chen, C.E. Small, C.M. Amb, J. Subbiah, T.H. Lai, S.W. Tsang, J.R. Manders, J.R. Reynolds, F. So, Inverted polymer solar cells with reduced interface recombination. Adv. Energy Mater. 2(11), 1333-1337 (2012). doi:10.1002/aenm.201200184

51. H. Zeng, G. Duan, Y. Li, S. Yang, X. Xu, W. Cai, Blue luminescence of $\mathrm{ZnO}$ nanoparticles based on non-equilibrium processes: defect origins and emission controls. Adv. Funct. Mater. 20(4), 561-572 (2010). doi:10.1002/adfm.200901884

52. T.P. Osedach, N. Zhao, S.M. Geyer, L.Y. Chang, D.D. Wanger, A.C. Arango, M.C. Bawendi, V. Bulovic, Interfacial recombination for fast operation of a planar organic/QD infrared photodetector. Adv. Mater. 22(46), 5250-5254 (2010). doi:10.1002/ adma.201002589

53. J.R. Sizelove, Residual native shallow donor in $\mathrm{ZnO}$. Phys. Rev. Lett. 82(12), 2552-2555 (1998). doi:10.1103/PhysRevLett.82. 2552 